\title{
Antiadherence and Antimicrobial Properties of Silver Nanoparticles against Streptococcus mutans on Brackets and Wires Used for Orthodontic Treatments
}

\author{
León Francisco Espinosa-Cristóbal ${ }^{D},{ }^{1}$ Natalie López-Ruiz, ${ }^{2}$ Denisse Cabada-Tarín, \\ Simón Yobanny Reyes-López $\mathbb{D}^{3}{ }^{3}$ Armando Zaragoza-Contreras, ${ }^{4}$ \\ Daniel Constandse-Cortéz, ${ }^{1}$ Alejandro Donohué-Cornejo, ${ }^{1}$ Karla Tovar-Carrillo, ${ }^{1}$ \\ Juan Carlos Cuevas-González $\mathbb{D}^{1}{ }^{1}$ and Takaomi Kobayashi ${ }^{5}$ \\ ${ }^{1}$ Master Program in Dental Sciences, Department of Dentistry, Biomedical Science Institute, Autonomous University of Ciudad Juarez \\ (UACJ), Envolvente del PRONAF and Estocolmo Avenues, 32310 Juárez, CHIH, Mexico \\ ${ }^{2}$ Program in Orthodontics, Department of Dentistry, Biomedical Science Institute, Autonomous University of Ciudad Juarez (UACJ), \\ Envolvente del PRONAF and Estocolmo Avenues, 32310 Juárez, CHIH, Mexico \\ ${ }^{3}$ Biomedical Science Institute, Autonomous University of Ciudad Juarez (UACJ), Envolvente del PRONAF and Estocolmo Avenues, \\ 32310 Juárez, CHIH, Mexico \\ ${ }^{4}$ Department of Engineering and Materials Chemistry, Centro de Investigación en Materiales Avanzados (CIMAV), Chihuahua, \\ CHIH, Mexico \\ ${ }^{5}$ Department of Materials Science and Technology, Nagaoka University of Technology (NUT), Nagaoka, Japan
}

Correspondence should be addressed to León Francisco Espinosa-Cristóbal; leohamet@hotmail.com

Received 21 March 2018; Accepted 27 May 2018; Published 5 July 2018

Academic Editor: Victor M. Castaño

Copyright ( 2018 León Francisco Espinosa-Cristóbal et al. This is an open access article distributed under the Creative Commons Attribution License, which permits unrestricted use, distribution, and reproduction in any medium, provided the original work is properly cited.

\begin{abstract}
White spot lesions (WSLs) are very frequent alterations during orthodontic treatments causing demineralization of the dental enamel. Various dental treatments have been developed to prevent WSLs; the prevalence and incidence of these lesions remain significantly high. Although silver nanoparticles (AgNPs) have demonstrated good inhibitory effects against several microorganisms, more studies about antiadherence activity on different orthodontic appliance surfaces are necessary. To determine the inhibitory effect and antiadherence activity of AgNPs on the adhesion of $S$. mutans on surfaces of brackets and wires for orthodontic therapies, two sizes of AgNPs were prepared and characterized. The evaluation of $S$. mutans adhesion was performed with microbiological assays on surfaces of brackets and orthodontic modules in triplicate. Topographic characteristics of orthodontic brackets and wires were made by scanning electron and atomic force microscopies. All AgNP samples inhibited S. mutans adhesion; however, the smaller AgNPs had better inhibition than the larger ones. The presence of the module influenced the adhesion of $S$. mutans but not in the activity of AgNPs. The AgNPs used in this study showed to have good antimicrobial and antiadherence properties against $S$. mutans bacteria determining its high potential use for the control of WSLs in orthodontic treatments.
\end{abstract}

\section{Introduction}

Dental caries is the most prevalent and multifactorial oral disease and still considered as a serious worldwide oral health problem [1]. The dental caries starts commonly its demineralization process on the dental enamel surfaces presenting opaque and white colors called to this stage as a white spot lesion (WSL) [2]. The development of WSLs is generally associated to prolonged dental plaque accumulation on the dental surfaces [3] and factors like 
diet, deficiency in calcium, phosphate, fluoride, and bicarbonate levels; specific medical and dental as well as genetic characteristics might be involved [3, 4]. Streptococcus mutans (S. mutans) has been considered the principal oral pathogen involved in the development of dental caries [5]; however, these bacteria have also been associated with other systemic diseases, such as bacteremia and infective endocarditis because of its great ability of the bacteria to adhere to tooth surfaces [6, 7]. Various scientific reports have determined that the orthodontic treatments significantly increase the risk of WSLs by the poor oral hygiene associated with more retentive surface area for food and limited oral hygiene skills $[3,8,9]$; however, other factors as dental susceptibility and chemical conditions could also be associated [10]. This is a clinical problem resulting in an unacceptable esthetic presentation that, in some severe cases, may require restorative treatments [11]. Despite hygiene therapies for the control of dental caries/WSLs, the frequency of WSLs in orthodontic treatments remains significantly high. Several studies have demonstrated that from $2 \%$ up to $96 \%$ of the patients with this kind of therapies could strongly develop conditions to increase the risk of WSLs in subjects with orthodontic appliances $[3,11-13]$; indicating, in some cases, that more than $50 \%$ of subjects with fixed orthodontic appliances might experience an increased risk in the number of WSLs during the orthodontic treatment [14]. This is a clinical problem that might create an unacceptable esthetic alteration that, in some severe cases, may involve restorative treatments [11]. Dental protocols for the prevention and control of WSLs based on fluoride tools have been the most successful treatments [12, 13]; moreover, other alternative protocols using innovating varnishes have recently demonstrated to have different physicochemical properties to the control of the development of incipient dental caries $[14,15]$. Recently, silver nanoparticles (AgNPs) have been shown to be materials with excellent antimicrobial properties in a wide variety of microorganisms [6, 16-19]. In the orthodontic field, studies have incorporated AgNPs $(17 \mathrm{~nm})$ into orthodontic elastomeric modules, orthodontic brackets and wires, and others, against a wide variety of bacterial species concluding that these orthodontic appliances with AgNPs could potentially combat the dental biofilm decreasing the incidence of dental enamel demineralization during and after the orthodontic treatments [20-23]. However, there is no information that has evaluated the antimicrobial effect and antiadherence activity of AgNPs against $S$. mutans bacteria on orthodontic bracket surfaces and its relationship with the presence of the elastomeric modules as well as different types of metallic orthodontic wires and the involved factors in the adherence of these bacteria. The aim of this work was to prepare and characterize two different sizes of AgNPs and evaluate its inhibition effect and antiadherence activity against the S. mutans strain on surfaces of orthodontic brackets and three different types of orthodontic wires.

\section{Materials and Methods}

2.1. Materials and Reagents. Silver nitrate $\left(\mathrm{AgNO}_{3}, \mathrm{CTR}\right.$ Scientific), gallic acid $\left(\mathrm{C}_{7} \mathrm{H}_{6} \mathrm{O}_{5}\right.$, Sigma-Aldrich), sodium hydroxide ( $\mathrm{NaOH}$, Jalmek Scientific ${ }^{\mathrm{TM}}$, Mexico), ammonium hydroxide $\left(\mathrm{NH}_{4} \mathrm{OH}\right.$, Jalmek Scientific, Mexico), MullerHinton (MH, BD ${ }^{\mathrm{TM}}$ Difco $^{\mathrm{TM}}$, USA), and S. mutans (ATCC ${ }^{\circledR}$, $\left.25175^{\mathrm{TM}}\right)$ strain were purchased, used, and stored according to manufacturer's recommendations. All used reagents were of analytical grades.

2.2. Synthesis of Silver Nanoparticles. Two different sizes of AgNPs were prepared following the method previously reported by Espinosa-Cristóbal et al. [16]. For the first sample, $0.01 \mathrm{M} \mathrm{AgNO}_{3}$ was dissolved in $100 \mathrm{~mL}$ of deionized water for $5 \mathrm{~min}$ under magnetic stirring in a $250 \mathrm{~mL}$ reaction vessel. After that, $10 \mathrm{~mL}$ of deionized water with $0.1 \mathrm{~g}$ of gallic acid was added to the solutions; then, the $\mathrm{pH}$ was immediately adjusted using $1.0 \mathrm{M} \mathrm{NaOH}$ raising to 11 . For the second sample, similar concentrations of $\mathrm{AgNO}_{3}$ were used; however, the amount of gallic acid was changed by $0.5 \mathrm{~g}$. The $\mathrm{pH}$ was finally adjusted with $\mathrm{NH}_{4} \mathrm{OH}$ raising a $\mathrm{pH}$ of 10 . Both samples were continually stirred for $10 \mathrm{~min}$ at room temperature.

2.3. Characterization of Silver Nanoparticles. Dynamic light scattering assay (DLS, Nanoparticle Analyzer, Nano Partica SZ-100 series, HORIBA Scientific Ltd., New Jersey, USA) operating with a DPSS laser at a wavelength of $532 \mathrm{~nm}$ using a scattering angle of 90 degrees, temperature of the holder $25^{\circ} \mathrm{C}$, and dispersion medium viscosity $0.895 \mathrm{mPa} / \mathrm{s}$ for 60 seconds for each sample was performed to evaluate size and zeta potential. Transmission electron microscopy (TEM, Phillips CM-200) at an accelerating voltage of $25 \mathrm{kV}$ determined the shape of particles; the elemental analysis was evaluated using the element energy dispersive spectroscopy (EDS) system (Team ${ }^{\mathrm{TM}}$ EDS System, EDAX).

2.4. S. mutans Suspension. A reference stock of S. mutans (ATCC 25175) was used as a standardized suspension containing approximately $1.3 \times 10^{8} \mathrm{CFU} / \mathrm{mL}$, which was obtained by spectrometry (Eppendorf BioPhotometer Plus, Germany) using a wavelength of $550 \mathrm{~nm}$ and an optical density of 0.126 .

2.5. Antibacterial Assay. The antibacterial test used in this work was made according to the study previously reported [15] with modifications. Previously to the antimicrobial test and adherence testing, the identity of the microorganism was confirmed by polymerase chain reaction (PCR). Bacterial strain was cultured in Müller-Hinton broth $(\mathrm{MH}, \mathrm{BD}$ Difco, USA) by $18 \mathrm{~h}$ at $37^{\circ} \mathrm{C}$ before the test. Minimum inhibitory concentrations (MIC) were determined by incubating each microorganism in 96-well microdilution plates; $200 \mu \mathrm{L}$ of each AgNP dispersion was placed in the first column and it was diluted 1:1 with $\mathrm{MH}$ medium (containing 2\% of sucrose for oral bacteria) inoculated with $S$. mutans microorganism strain at $1.3 \times 10^{6} \mathrm{CFU} / \mathrm{mL}$; finally, plates were incubated at $37^{\circ} \mathrm{C}$ for $24 \mathrm{~h}$. After that, the last well that presented turbidity was considered as MIC. All antibacterial tests were made in triplicate.

2.6. Adherence Testing. The adherence testing was performed in a laminar air-flow chamber. Sterilized stainless steel 
orthodontic brackets (upper central incisors, ICS ${ }^{\mathrm{TM}}$, Ah-Kim$\mathrm{Pech}^{\mathrm{TM}}$ ) with and without orthodontic elastomeric modules (Ah-Kim-Pech) and three different types of orthodontic wires ( $3 \mathrm{~cm}$ for each), nickel-titanium (NiTi, Ah-Kim-Pech), copper-nickel-titanium (CuNiTi, Ah-Kim-Pech), and stainless steel (SS, Ah-Kim-Pech), were used. Brackets, elastic modules, or orthodontic wires with fractures, bent, twisted, wry, or other any topographic alterations were excluded. In a laminar air-flow chamber (aseptic environment), the groups were randomly divided, according to the presence of AgNP, in 4 groups: (1) $8.1 \mathrm{~nm} \mathrm{SNP,} \mathrm{(2)} 20.1 \mathrm{~nm} \mathrm{SNP,} \mathrm{(3)} \mathrm{neg-}$ ative control (deionized water), and (5) positive control (no bacteria). Each orthodontic device was individually placed into Eppendorf tubes for each group, then $1 \mathrm{~mL}$ of $\mathrm{MH}$ broth (BD Difco, USA) and $825 \mu \mathrm{L}$ of each AgNP suspension were added; $125 \mu \mathrm{L}$ of deionized water was used as positive and negative control, respectively. Finally, $100 \mu \mathrm{L}$ of standardized suspension of $S$. mutans was added to all tubes, sealed, and incubated for $24 \mathrm{~h}$ at $37^{\circ} \mathrm{C}$. After this incubation period, orthodontic devices were transferred into tubes containing $1 \mathrm{~mL}$ of phosphate-buffered saline solution (PBS) and sonicated for $5 \mathrm{~min}$; poorly adhered bacteria cells were thus dispersed. This bacterial suspension was diluted 1000 times with PBS solution, and $100 \mu \mathrm{L}$ of each suspension was placed and extended on $\mathrm{MH}$ agar plates. After $48 \mathrm{~h}$ at $37^{\circ} \mathrm{C}$, colony forming unit count $(\mathrm{CFU} / \mathrm{mL})$ was determined. Adherence testing was made in triplicate in three different times.

2.7. Scanning Electron Microscopy and Atomic Force Microscopy Analyses. Scanning electron microscopy (SEM) and atomic force microscopy (AFM) were used to explore topographic characteristics of orthodontic wires. New and dried samples of each type of wire were used for topographic evaluations using environmental conditions. The wires were examined by SEM analysis (JEOL, JSM-5300 LV, Japan) and operated at an accelerating voltage of $15 \mathrm{kV}$ with magnifications of $\times 100, \times 200$, and $\times 5000$ in magnitudes, and AFM analysis with use of a SI-DF3-A cantilever, a spring contact of $3.0 \mathrm{~N} / \mathrm{m}$, a level length of $450 \mu \mathrm{m}$, and a resonant frequency of $33 \mathrm{kHz}$ was used.

2.8. Statistical Analysis. All data of adherence testing were expressed as the mean \pm standard deviation. Significant differences between AgNP samples, orthodontic brackets, and orthodontic wire groups were analyzed by Mann-Whitney $U$ test for nonparametric values (StatView software, SAS Institute Inc., v5.0.1, Cary, NC, USA). Groups were considered significantly different when $p<0.05$.

\section{Results}

3.1. Characterization of Silver Nanoparticles. The physical and chemical characteristics of AgNP are shown in Table 1. Uniform sizes, spherical shapes, and good particle distributions were consistently observed for both AgNP samples (Figure 1). According to the DLS results, single, centered, and thin peaks were found in smaller $(8.1 \pm 3.4 \mathrm{~nm})$ and larger $(20.1 \pm 10 \mathrm{~nm})$ AgNP samples, respectively. The zeta potential results indicate that both AgNP samples
TABLE 1: Characterization of silver nanoparticles.

\begin{tabular}{lcccc}
\hline $\begin{array}{l}\text { AgNP } \\
(\mathrm{nm})\end{array}$ & $\begin{array}{c}\text { Diameter } \\
\text { DLS }(\mathrm{nm})\end{array}$ & Shape & $\begin{array}{c}\text { Initial } \\
\text { concentration } \\
(\mu \mathrm{g} / \mathrm{mL})\end{array}$ & $\begin{array}{c}\text { Zeta } \\
\text { potential } \pm \mathrm{ZD}^{*} \\
(\mathrm{mV})\end{array}$ \\
\hline 8.1 & $8.1 \pm 3.4$ & Spherical & 1070 & $-19.1 \pm 52.5$ \\
20.1 & $20.1 \pm 10$ & Spherical & 1070 & $-36.5 \pm 5.7$ \\
\hline
\end{tabular}

DLS: dynamic lighting scattering. * Zeta potential is expressed in average and zeta deviation.

had negative values; however, the larger AgNP samples $(-36.5 \pm 5.7 \mathrm{mV})$ had slightly higher electrical charges than smaller Ag particles $(-19.1 \pm 52.5 \mathrm{mV})$.

3.2. Antibacterial Test. Figure 2 shows the antimicrobial activity of AgNP. Both sizes of AgNP (8.1 and 20.1 nm) showed growth inhibition activity of $S$. mutans bacteria (Figure 2). Therefore, smaller AgNP samples (16.7 $\pm 0.0 \mu \mathrm{g} /$ $\mathrm{mL}$ ) had consistently better antimicrobial inhibition effects against $S$. mutans strain compared to larger Ag particles $(66.8 \pm 0.0 \mu \mathrm{g} / \mathrm{mL})$ showing significant differences between them $(p<0.05)$.

3.3. Adherence Testing. The antiadherence activity of AgNPs on orthodontic brackets is shown in Figure 3. According to the presence of the orthodontic modules (Figure 3(a)), the antiadherence effect of AgNPs was not significantly affected using modules $(94.75 \pm 166.1 \mathrm{CFU} / \mathrm{mL})$ than orthodontic brackets with no module $(91.3 \pm 160.0 \mathrm{CFU} / \mathrm{mL})(p>0.05)$. Furthermore, both sizes of AgNP samples (8.1 and $20.1 \mathrm{~nm})$ had significantly better antiadherence activity $(4.3 \pm 2.8 \mathrm{CFU} / \mathrm{mL}$ for smaller particles and $5 \pm 8.6 \mathrm{CFU} / \mathrm{mL}$ for larger particles) than the control groups $(356 \pm 25.0 \mathrm{CFU} /$ $\mathrm{mL})$, even with the presence of orthodontic modules $(4.3 \pm 3.0$ and $5 \pm 3.4 \mathrm{CFU} / \mathrm{mL}$, resp.) (Figure 3(b)). Although the presence of the orthodontic module increased slightly the adherence of $S$. mutans strain on the surface of orthodontic bracket but with no significant differences (Figure 3(d)), smaller and larger Ag particles showed significantly similar antiadherence activity on the $S$. mutans strain compared to the control groups even with the presence of orthodontic modules (Figure 3(c)).

The antiadherence activity of AgNPs on different types of orthodontic wires is shown in Figure 4. Both sizes of AgNP samples had statistically good adherence inhibition of the $S$. mutans strain for all types of orthodontic wires $(\mathrm{SS}=26.1-52.6 \pm 2.6-2.8, \quad \mathrm{NiTi}=15.1-49.6 \pm 2.1-2.5, \quad$ and $\mathrm{CuNiTi}=89.1-287.8 \pm 2.1-2.6)$ compared with the control groups $(\mathrm{SS}=346.7 \pm 3.3 \mathrm{CFU} / \mathrm{mL}, \mathrm{NiTi}=342.3 \pm 39.1$, and $\mathrm{CuNiTi}=376.2 \pm 18.3 \mathrm{CFU} / \mathrm{mL})$. Also, significant differences were found between orthodontic wire groups in which the CuNiTi group showed statistically more increased bacterial adhesion activity $(188.5 \pm 157.5 \mathrm{CFU} / \mathrm{mL})$ compared to the $\mathrm{NiTi}(101.8 \pm 147.3 \mathrm{CFU} / \mathrm{mL})$ and SS (101.9 $\pm 148.7 \mathrm{CFU} /$ $\mathrm{mL}$ ) wire groups (Figure 4(a)). It can be observed in Figure 4(b) that all sizes of AgNPs demonstrated significantly to have a good inhibition adherence activity for the three different types of orthodontic wire groups; however, smaller AgNPs $(8.1 \mathrm{~nm})$ showed better antiadherence properties 


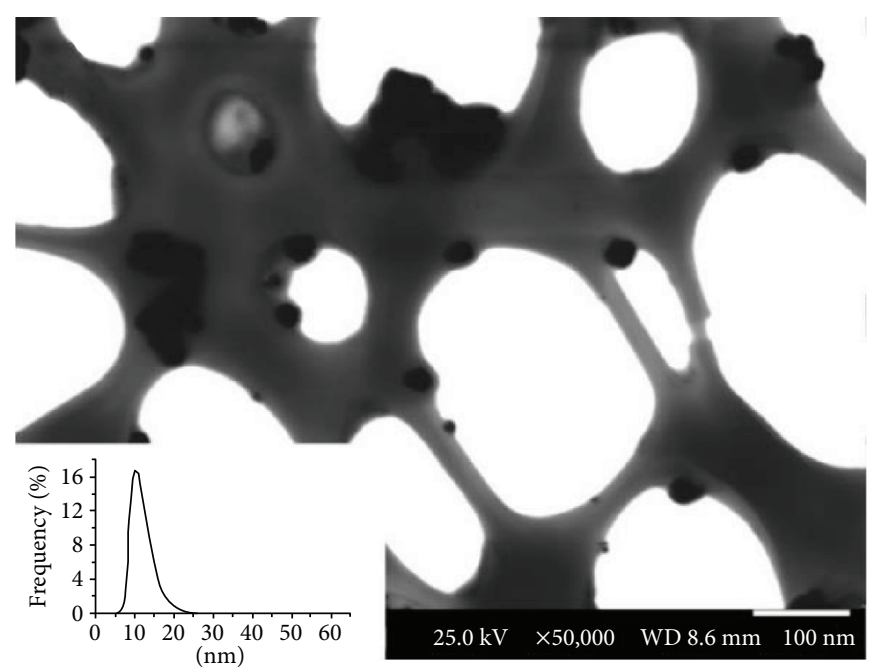

(a)

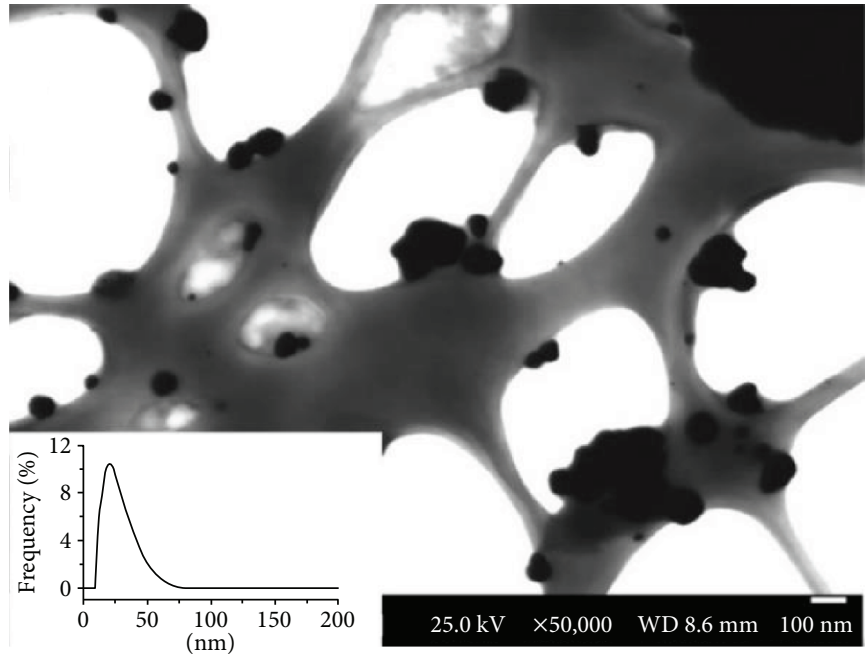

(b)

Figure 1: DLS and TEM results of AgNPs. (a) $8.1 \mathrm{~nm}$; (b) $20.1 \mathrm{~nm}$.

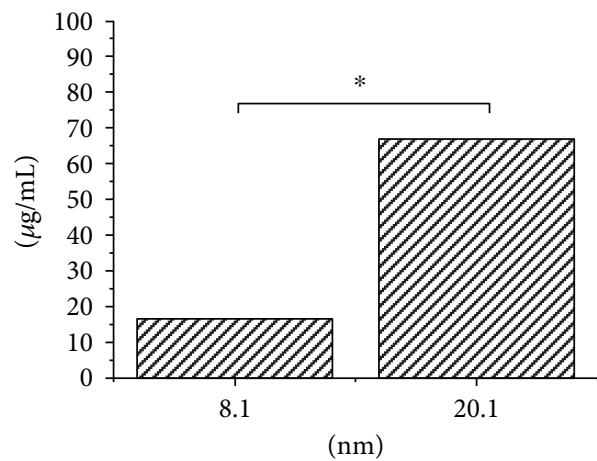

(a)

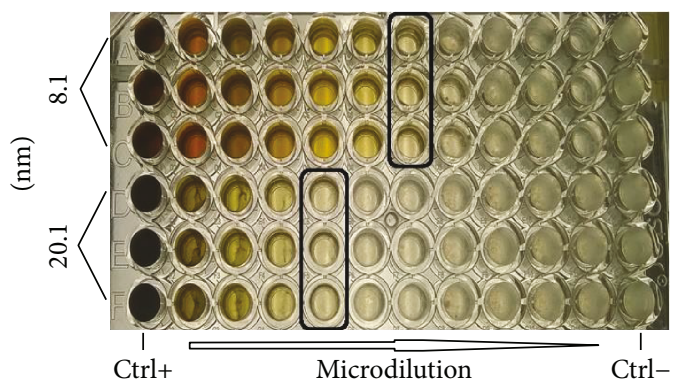

(b)

FIgURe 2: Antimicrobial assay. (a) Minimum inhibitory concentrations (average and standard deviation expressed in micrograms per milliliter); (b) 96-well plate used for MIC. Black asterisk indicates significant differences $(p<0.05)$. Black squares indicate minimum inhibitory concentrations. 


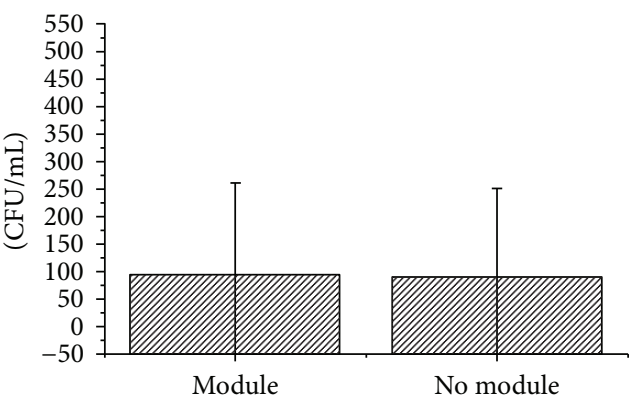

(a)

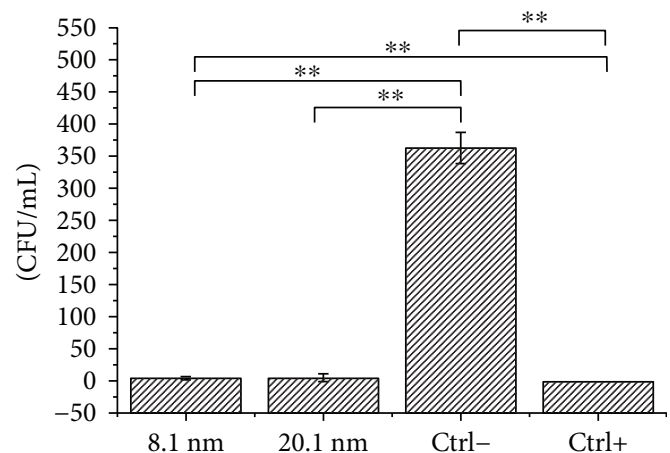

(c)

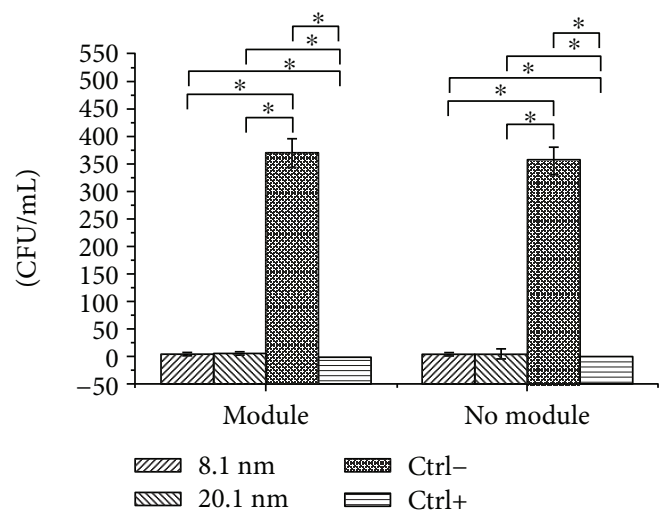

(b)

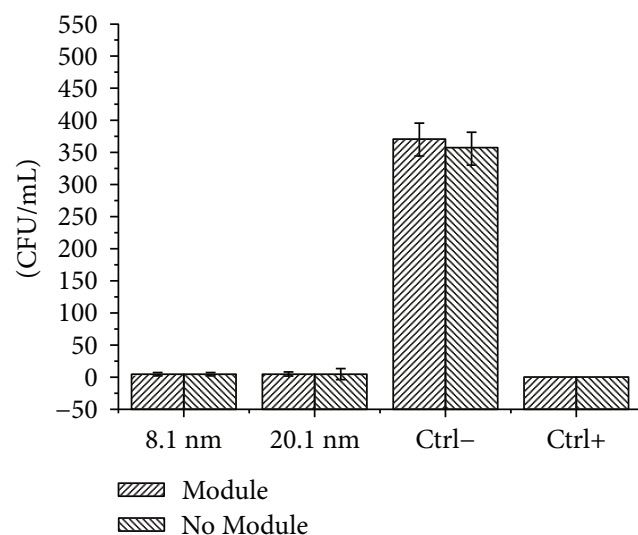

(d)

Figure 3: Adherence assay of AgNPs and S. mutans strain on orthodontic brackets. (a) Antiadherence activity with and without orthodontic modules; (b) antiadherence activity on orthodontic modules and AgNP samples; (c) antiadherence activity of AgNP samples; (d) antiadherence activity of AgNP samples and the presence of orthodontic modules. One asterisk indicates $p<0.05$; two asterisks indicate $p<0.01$.

than larger particle $(20.1 \mathrm{~nm})$ samples $(p<0.05)$. Moreover, both sizes of AgNPs, especially smaller Ag particles $(8.1 \mathrm{~nm})$, significantly promoted an increased adherence inhibition activity of $S$. mutans bacteria $(p<0.05)$, even successfully generating better bacterial adherence capacity of the AgNPs on surfaces of CuNiTi orthodontic wires (Figures 4(c) and 4(d)).

3.4. SEM and AFM Analyses. SEM and AFM analyses were performed to evaluate topographic conditions for each orthodontic wire. SEM and AFM micrographs of $\mathrm{NiTi}$, CuNiTi, and SS orthodontic wires are shown in Figures 5 and 6. SEM images revealed that the surfaces of CuNiTi wires showed more irregular topographic conditions (Figures 5(g) and 5(i)) compared to NiTi (Figures 5(d) and 5(f)) and SS (Figures 5(a) and 5(c)) wires. A great number of pores and well-distributed irregular cavity surfaces were significantly found in CuNiTi wires than the other types of orthodontic appliances. Additionally, poor topographic irregularities were slightly observed on NiTi and SS wire surfaces; however, SS orthodontic wires presented more marked zones with topographic irregularities and depressed areas as well as much more scratches (Figures 5(b) and 5(c)) compared to surfaces of NiTi wires (Figures 5(e) and 5(f)). On the other hand, it can be observed in two- and three-dimensional AFM images that the surfaces of orthodontic wires showed to have similar topography than SEM images in which CuNiTi wires had clearly more irregular and amorphous surfaces (Figure 6(c)) compared to SS and NiTi appliances (Figures 6(a) and 6(b), resp.). Also, SS and NiTi images obtained by AFM analysis (2D and 3D) agree with SEM results in which more smooth surfaces and scarce scratches with significant undermined were consistently observed (Figures 6(a) and 6(b)). Contrastively, roughness values of the orthodontic wires (data not shown) were relatively opposite in which the lineal roughness values (Figure 6, center images) were more increased in SS wires $(7.094 E+01 \mathrm{~nm})$, followed by $\mathrm{NiTi}$ wires $(6.234 E+01 \mathrm{~nm})$ and the lowest roughness value for CuNiTi wires $(3.116 E+01 \mathrm{~nm})$. These results indicate that the microbial adhesion ability of the $S$. mutans strains could be associated to the particular microtopographic conditions on the surface of the orthodontic wires, specifically with CuNiTi samples than nanometric characteristics involved in each orthodontic wire. 


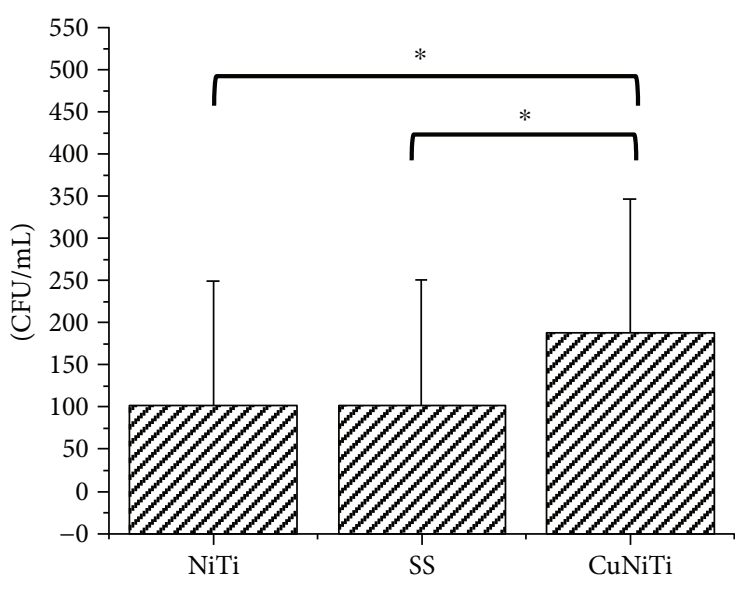

(a)

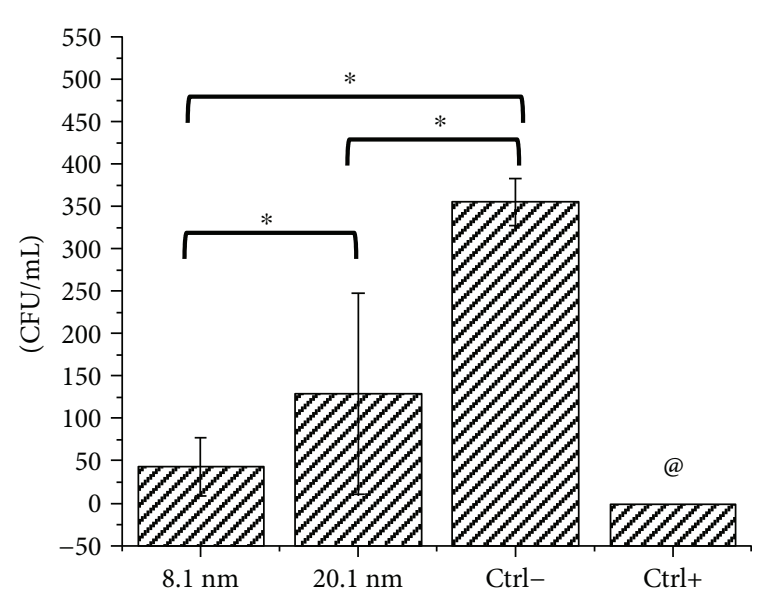

(c)

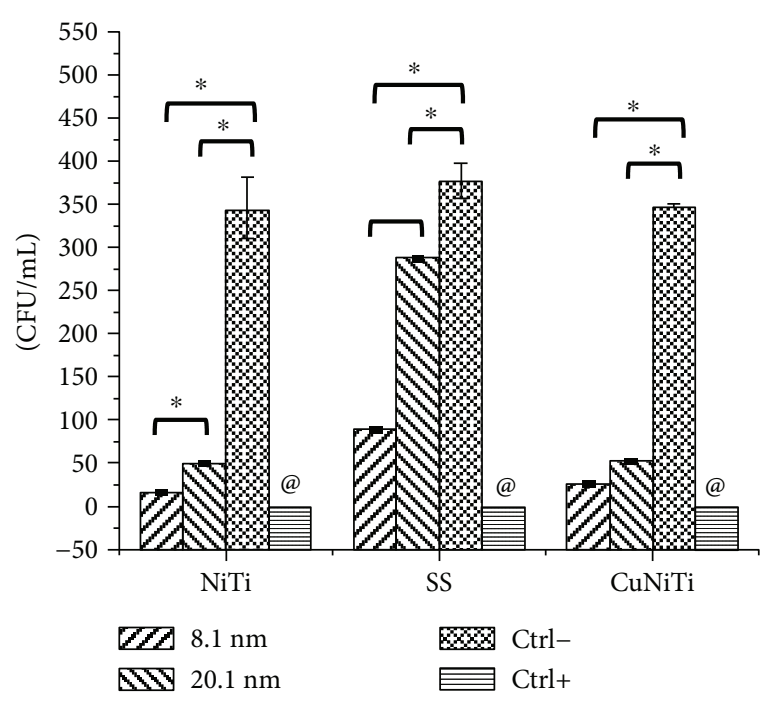

(b)

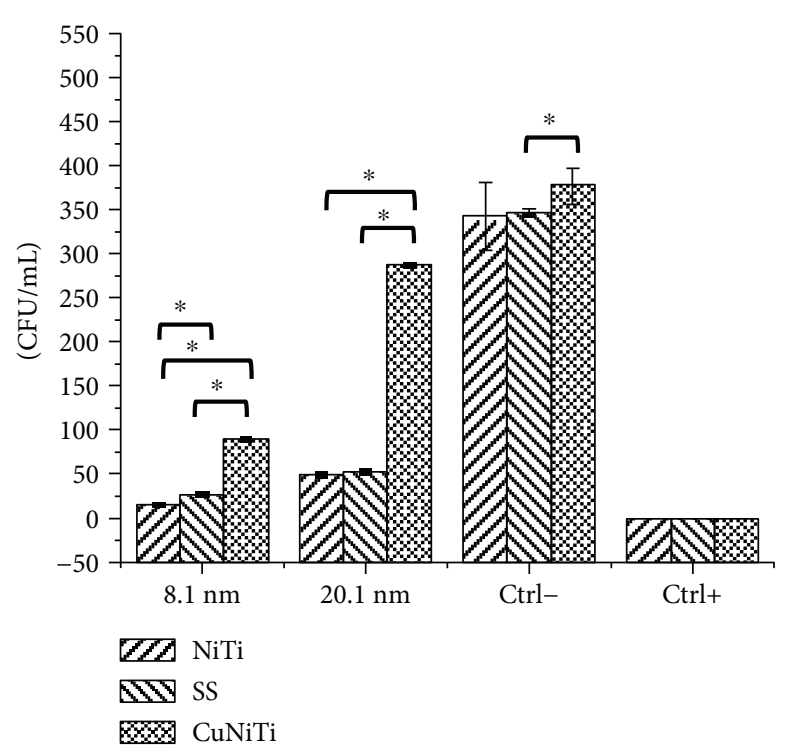

(d)

Figure 4: Adherence assay of AgNPs and S. mutans strain on orthodontic wires. (a) Antiadherence activity on wires; (b) antiadherence activity on orthodontic wires and AgNP samples; (c) antiadherence activity of AgNP samples; (d) antiadherence activity of AgNP samples and different orthodontic wires. $\mathrm{NiTi}=$ nickel-titanium; CuNiTi=copper-nickel-titanium; SS=stainless steel. One asterisk indicates $p<0.05$; @ indicates significant differences with all groups $(p<0.05)$.

\section{Discussion}

This study determined that the AgNPs can significantly inhibit the bacterial adherence of the $S$. mutans strain on the surfaces of orthodontic bracket and wire appliances finding that the smaller AgNP samples demonstrated statistically to have the most important antiadherence activities for orthodontic brackets and wires $(p<0.05)$. Although the presence of the orthodontic module increased the adherence ability of the $S$. mutans on the bracket surfaces, the adherence inhibition activity of the AgNP samples was not significantly limited by the presence of these elastomeric orthodontic appliances $(p>0.05)$. Moreover, the CuNiTi orthodontic wires showed significantly to have specific topographic conditions to increase the adherence activity of the S. mutans bacteria compared to other orthodontic appliances $(p<0.05)$, in which particular micro- and macroscopic conditions were related to facilitate much better the microbial adherence ability of the $S$. mutans bacteria than NiTi and SS wires. In general, both sizes of AgNPs used in this study showed good antiadherence properties of the $S$. mutans strains, even with the presence of orthodontic appliances that could tend to improve the adherence ability of this bacterial strain.

Nowadays, there are several studies that demonstrate the antimicrobial activity of the AgNPs; therefore, there are no enough studies that have evaluated the effect of the AgNPs on the adhesion of $S$. mutans bacteria on surfaces of brackets and wires used for conventional orthodontic treatments. Various studies have shown that a coverage of AgNPs in 


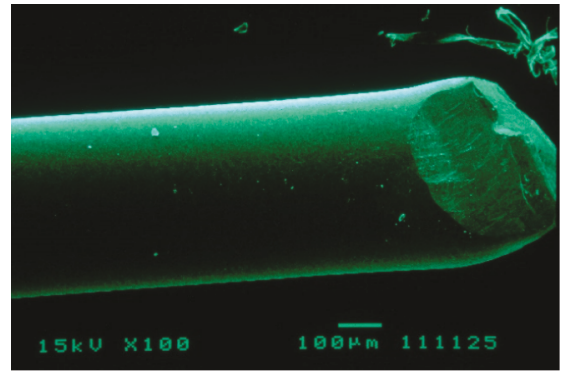

(a)

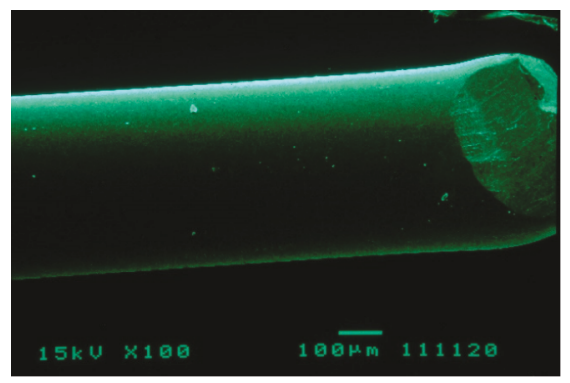

(d)

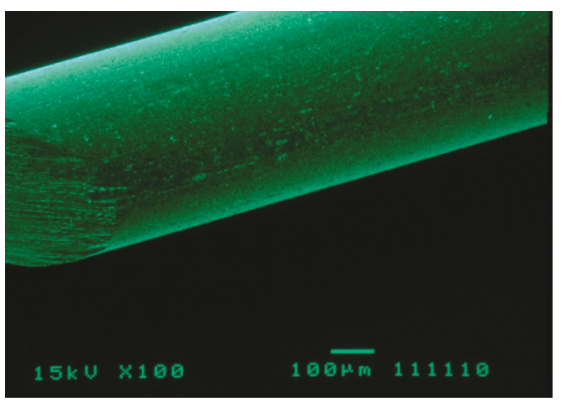

(g)

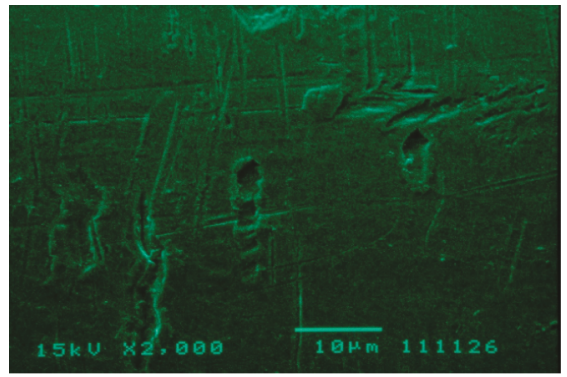

(b)

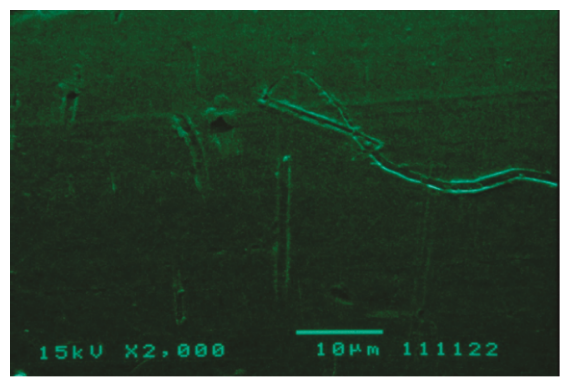

(e)

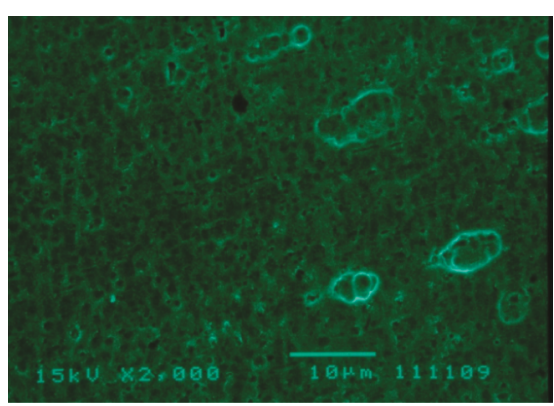

(h)

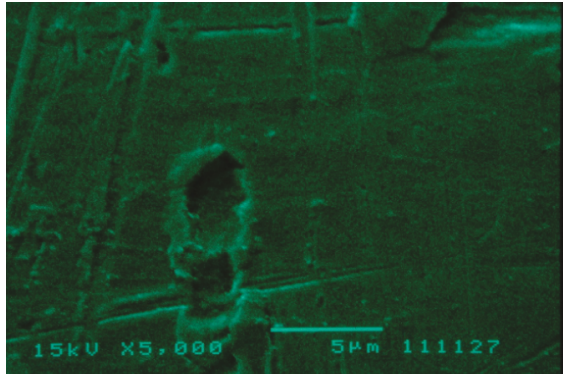

(c)

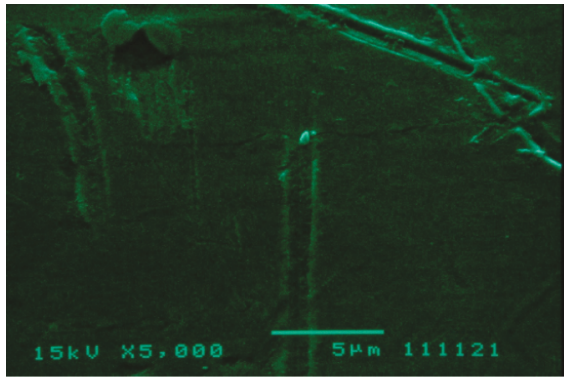

(f)

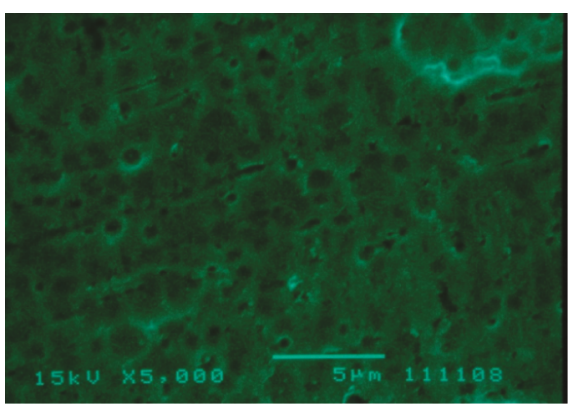

(i)

FIGURE 5: SEM micrographs of orthodontic wires. (a) Stainless steel, $\times 100$; (b) stainless steel, $\times 2000$; (c) stainless steel, $\times 5000$; (d) nickeltitanium, $\times 100$; (e) nickel-titanium, $\times 2000$; (f) nickel-titanium, $\times 5000$; (g) copper-nickel-titanium, $\times 100$; (h) copper-nickel-titanium, $\times 2000$; (i) copper-nickel-titanium, $\times 5000$.

human dentin can prevent biofilm formation on the surface of the dentin as well as inhibit bacterial growth around it $[18,24]$. According to the characterization of AgNPs, it is very well known that particles with zeta potential values between +30 and $-30 \mathrm{mV}$ are considered a stable suspension limiting the agglomeration $[25,26]$. It has been reported that the concentration of $\mathrm{AgNO}_{3}(0.01,0.1$, and $0.5 \mathrm{M})$ can affect the size of silver nanoparticles $(20,25$, and $11 \mathrm{~nm})$ and the zeta potential values $(-26.37,-37.95$, and -28.23 , resp.); moreover, the $\mathrm{pH}$ values in the solution could also promote a high risk of agglomeration when $\mathrm{pH}$ values $<7$ were used, while $\mathrm{pH}$ values $>7$ could have better conditions for nonagglomerated particles [26]. Our results from characterization indicate that all AgNP samples had generally good distribution and uniform sizes and shapes, while the potential zeta results suggest that smaller AgNPs could have an increased risk to be agglomerated due to low electrical charge $(-19.1 \pm 52.5 \mathrm{mV})$ compared to larger particles $(-36.5 \pm 5.7 \mathrm{mV})$, agreeing with other reported studies that found similar results $[17,26,27]$. It is possible that $\mathrm{AgNO}_{3}$ concentration and different $\mathrm{pH}$ values as well as specific concentrations of gallic acid (stabilizer agent) for each AgNP sample can generate specific electrical charges promoting better properties associated with particle stability. On the other hand, studies have determined that the smaller AgNPs can have the ability to release more silver ions, having a greater surface area that increases its antimicrobial effect $[17,18,24]$, adhering to the cell death [28]. Our study determined significant and good adherence inhibition and antimicrobial activities of AgNP samples against $S$. mutans strains on surfaces of wires and orthodontic brackets $(p<0.05)$. It is possible that the AgNPs penetrate the cell membrane of $S$. mutans affecting the metabolic system of these bacteria, preventing the production of extracellular polysaccharides (bacterial adhesion agents) and specific metabolic processes for the development of $S$. mutans binding structures on surfaces and other bacteria $[17,18,24,29]$. Also, a recent study evaluated the antimicrobial properties of AgNPs $(17 \mathrm{~nm})$ included in orthodontic elastomeric modules against $S$. mutans, Lactobacillus casei ( $L$. casei), Staphylococcus aureus (S. aureus), and Escherichia coli (E. coli), concluding that the use of AgNPs immersed into 

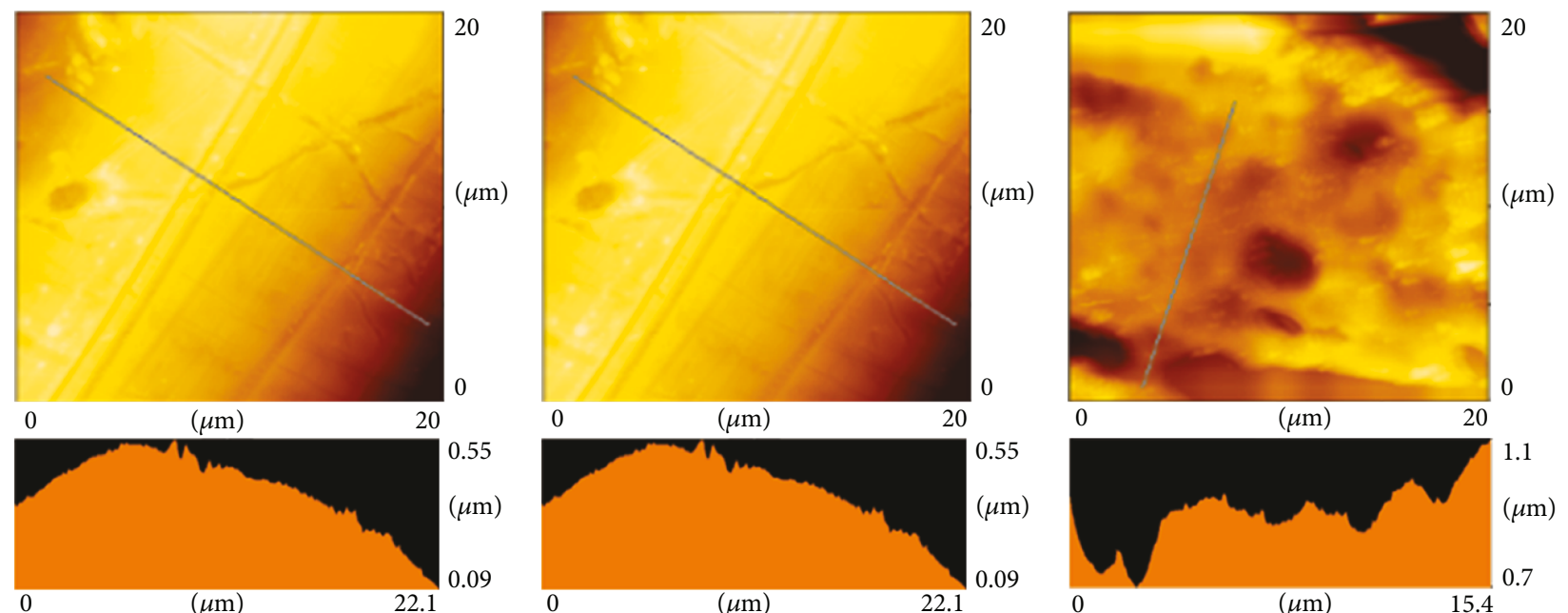

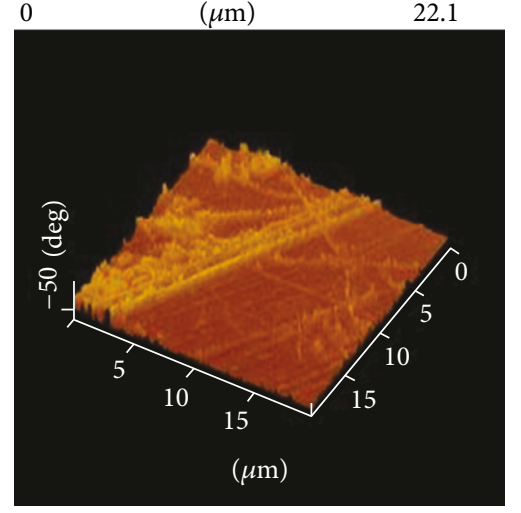

(a)

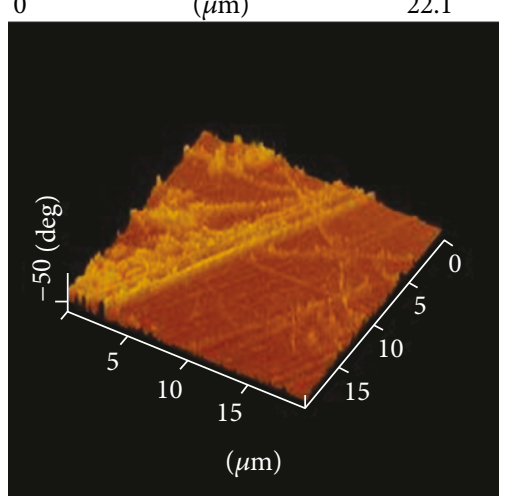

(b)
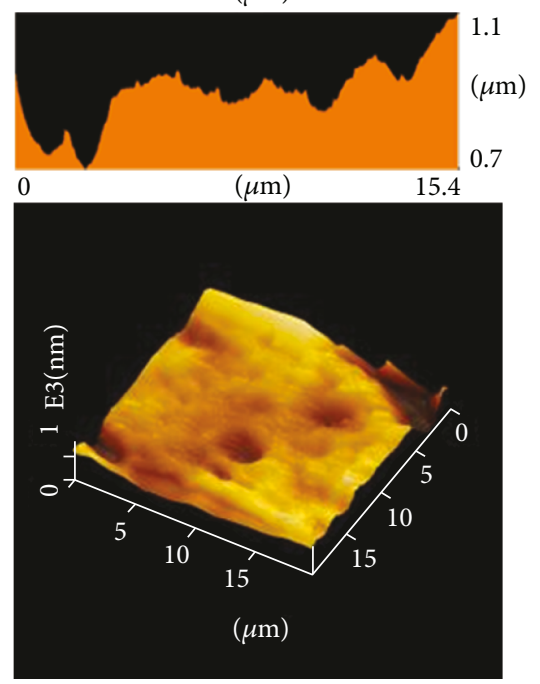

(c)

Figure 6: AFM micrographs of orthodontic wires. (a) Stainless steel; (b) nickel-titanium; (c) copper-nickel-titanium. 2D and 3D images are presented in area of $20 \times 20 \mu \mathrm{m}$. Lineal roughness (center images) was determined according to the lineal length marked in each $2 \mathrm{D}$ image.

elastomeric modules could potentially combat the dental biofilm decreasing the incidence of dental enamel demineralization during the orthodontic treatments [20]. Other study evaluated, through an in vivo experimental design, the antimicrobial activity on $S$. mutans bacteria and the ion release capacity of nanosilver-coated orthodontic brackets; these authors concluded that AgNP-coated brackets could significantly help to decrease the presence of spot lesions during fixed orthodontic treatments, even may have a potential solution for systemic compromised patients such as immune deficiency, diabetics, and subacute bacterial endocarditis. [21]. Our results agree with these results indicating that both sizes of AgNP samples have significant ability to inhibit the adherence capacity of $S$. mutans bacteria on surfaces of elastomeric modules and orthodontic brackets, even for these orthodontic brackets and elastomeric modules crisscrossed $(p<0.05)$. On the other hand, the antiadherence activity of AgNPs against $S$. mutans strain on various orthodontic wire surfaces was also determined. Authors have reported that SS and NiTi orthodontic wires with silver coatings as well as silver-coated titanium films showed good antiadherence and antimicrobial properties against Lactobacillus acidophilus (L. acidophilus) and S. mutans, respectively. Those results indicated that the SS $(220.90 \pm 30.73 \mathrm{CFU} / \mathrm{mL})$ and $\mathrm{NiTi}$ $(203.20 \pm 41.94 \mathrm{CFU} / \mathrm{mL})$ orthodontic wires with silver coatings as well as titanium films with silver had significantly more antiadherence and antimicrobial activities compared to wire samples with no coating $(836.60 \pm 48.97$ and 748.90 $\pm 35.64 \mathrm{CFU} / \mathrm{mL}$, resp.), determining that the use of silver on orthodontic wires and titanium films might prevent the accumulation of dental plaque and the development of dental caries during the orthodontic treatments [22, 23]. Our results suggest similar conclusions, in which, both AgNP samples against S. mutans bacteria on SS (101.9 $\pm 148.7 \mathrm{CFU} / \mathrm{mL}), \quad \mathrm{NiTi} \quad(101.8 \pm 147.3 \mathrm{CFU} / \mathrm{mL})$, and CuNiTi $(188.5 \pm 157.5 \mathrm{CFU} / \mathrm{mL})$ orthodontic wires had statistically better antimicrobial and antiadherence properties compared to the control groups $(346.7 \pm 3.3,342.3 \pm 39.1$, and $376.2 \pm 18.3 \mathrm{CFU} / \mathrm{mL}$, resp.), associating these AgNP properties with the particle size $(p<0.05)$. These results suggest that the action mechanism of antimicrobial and antiadherence activities of AgNPs is due to the interaction of silver with thiol and amino groups located in enzymes and proteins of the bacterial cell playing an important role in the metabolic function and the possibility of the induction of a bacterial apoptosis-like response leading to the bacterial cell death $[16,19,20,24,30]$; however, the large surface area of smaller AgNP samples might also be involved $[6,31]$.

On the other hand, in an attempt to explore the principal risk factors involved in the increased adherence activity of $S$. 
mutans bacteria in different orthodontic wire surfaces, micro- and nanotopographies analyzed by SEM and AFM instruments were evaluated. Various studies have evaluated chemical and mechanical properties in the different types of $\mathrm{NiTi}$ and $\mathrm{CuNiTi}$ wires used for orthodontic treatments. Those results determined that the surface morphology of NiTi samples had the lowest wire-surface roughness and the best chemical and mechanical properties, while those that presented the greatest and inadequate wire-surface roughness, deactivation loadings biologically less favorable in relation to the other heat-activated $\mathrm{NiTi}$ archwires, more degradation within the oral cavity, the highest corrosion risk and others, were also reported for CuNiTi wires [32-35]. Our results agree with those reported studies in which SEM and AFM images demonstrated that the CuNiTi wires presented more irregular surface topography with large amount of micropores and well-defined and irregular cavity surfaces, while NiTi and SS archwires had generally more smooth surfaces with slight scratches on their surfaces (Figures 5 and 6). This information suggests that the particular topographic and chemical conditions in each type of orthodontic wire could be considered as a relevant risk factor to promote significant irregular surfaces and more superficial area on the surface of orthodontic wires, principally in CuNiTi samples $[32,33]$, permitting an increased bacterial adherence of S. mutans microorganism in regular conditions [6]. It is possible that the effect of AgNPs in the adherence activity of $S$. mutans bacteria on these orthodontic brackets and wires is due to various possible risk factors, such as particular microbiology characteristics of the microorganism, physical and chemical conditions of the used orthodontic appliances, and specific physicochemical properties of the AgNPs, in which several specific activities might synergistically be involved in the adherence activity of the S. mutans bacteria in these orthodontic tools. Although our results might support this possible argument, more studies that determine the effect of AgNPs according to the corrosion level, topographic alterations, roughness, ion release, and other important properties of the most used orthodontic archwires should be investigated.

In addition, the AgNPs have also been used for other different applications in the orthodontic field; the results of those investigations demonstrate that the orthodontic appliances with AgNPs have the ability to improve their antibacterial properties in several types of microorganisms involved in the white spots [36-39]. Our results suggest that the AgNP samples used in this study have the potential to be an excellent antimicrobial alternative with antiadherence properties that might facilitate the prevention of white spots caused by the $S$. mutans bacteria during the orthodontic therapeutics for the most conventional orthodontic appliances. It is possible that mouthwashes or varnishes containing AgNPs could be regularly used during conventional dental hygiene applied directly on the surface of orthodontic appliances, helping the bacterial mechanical removal promoted by toothbrushes promoting a delay in bacterial adhesion and, consequently, low frequency of WSLs. Nonetheless, other scientific studies are undoubtedly needed to understand the effect of AgNP samples on the roughness, topography, corrosion, ion release, and other relevant to conditions of brackets and orthodontic wires in different simulated oral environments as well as the action mechanism of these metallic nanoparticles to inhibit the bacterial growth capacity and intervene in the bacterial adherence of the S. mutans microorganism.

\section{Conclusions}

The AgNPs used in this study were shown to inhibit the bacterial adhesion and growth ability of $S$. mutans bacteria on surfaces of orthodontic brackets and different types of orthodontic wires. The identified factors associated to the antiadherence ability and the antimicrobial effect of AgNPs on all orthodontic appliances were principally smaller AgNPs and specific topographic conditions of CuNiTi wires. According to our understanding, this is the first study that determined the antiadherence activity of AgNPs against S. mutans bacteria on brackets and wires used for orthodontic treatments. Although more serious scientific studies must be made, this study suggests that the AgNPs have a high potential for biomedical applications in the control of dental caries in patients with orthodontic treatments.

\section{Data Availability}

The data obtained from this study can be found in the research archives of the Master's Program in Dental Sciences of the Autonomous University of Ciudad Juarez and can be requested through the corresponding author.

\section{Conflicts of Interest}

The authors declare that there is no conflict of interests regarding the publication of this paper.

\section{Acknowledgments}

The authors are grateful for the financial support for this work: Consejo Nacional de Ciencia y Tecnología (CONACYT) (Grant nos. 591978 and 591981) and Programa para el Desempeño Profesional Docente (PRODEP).

\section{References}

[1] M. Al-Darwish, W. El Ansari, and A. Bener, "Prevalence of dental caries among 12-14 year old children in Qatar," The Saudi Dental Journal, vol. 26, no. 3, pp. 115-125, 2014.

[2] K. C. Julien, P. H. Buschang, and P. M. Campbell, "Prevalence of white spot lesion formation during orthodontic treatment," The Angle Orthodontist, vol. 83, no. 4, pp. 641-647, 2013.

[3] M. K. Eltayeb, Y. E. Ibrahim, I. A. El Karim, and N. M. Sanhouri, "Distribution of white spot lesions among orthodontic patients attending teaching institutes in Khartoum," BMC Oral Health, vol. 17, no. 1, p. 88, 2017.

[4] S. Hadler-Olsen, K. Sandvik, M. A. El-Agroudi, and B. Ogaard, "The incidence of caries and white spot lesions in orthodontically treated adolescents with a comprehensive caries prophylactic regimen-a prospective study," The European Journal of Orthodontics, vol. 34, no. 5, pp. 633-639, 2012. 
[5] K. A. Plonka, M. L. Pukallus, A. G. Barnett, L. J. Walsh, T. H. Holcombe, and W. K. Seow, "Mutans streptococci and lactobacilli colonization in predentate children from the neonatal period to seven months of age," Caries Research, vol. 46, no. 3, pp. 213-220, 2012.

[6] Á. M. Martínez-Robles, J. P. Loyola-Rodríguez, N. V. ZavalaAlonso et al., "Contribution of the interaction of Streptococcus mutans serotype $k$ strains with fibrinogen to the pathogenicity of infective endocarditis," Nanomaterials, vol. 6, no. 7, 2016.

[7] R. Nomura, M. Otsugu, S. Naka et al., "Contribution of the interaction of Streptococcus mutans serotype $k$ strains with fibrinogen to the pathogenicity of infective endocarditis," Infection and Immunity, vol. 82, no. 12, pp. 5223-5234, 2014.

[8] N. Sagarika, S. Suchindran, S. Loganathan, and V. Gopikrishna, "Prevalence of white spot lesion in a section of Indian population undergoing fixed orthodontic treatment: an in vivo assessment using the visual International Caries Detection and Assessment System II criteria," Journal of Conservative Dentistry, vol. 15, no. 2, pp. 104-108, 2012.

[9] D. Shungin, A. I. Olsson, and M. Persson, "Orthodontic treatment-related white spot lesions: a 14-year prospective quantitative follow-up, including bonding material assessment," American Journal of Orthodontics and Dentofacial Orthopedics, vol. 138, no. 2, pp. 136.e1-136.e8, 2010.

[10] R. Chatterjee and I. Kleinberg, "Effect of orthodontic band placement on the chemical composition of human incisor tooth plaque," Archives of Oral Biology, vol. 24, no. 2, pp. 97100, 1979.

[11] D. Sundararaj, S. Venkatachalapathy, A. Tandon, and A. Pereira, "Critical evaluation of incidence and prevalence of white spot lesions during fixed orthodontic appliance treatment: a meta-analysis," Journal of International Society of Preventive and Community Dentistry, vol. 5, no. 6, pp. 433-439, 2015.

[12] J. A. Cury and L. M. A. Tenuta, "Evidence-based recommendation on toothpaste use," Brazilian Oral Research, vol. 28, no. spe, pp. 1-7, 2014.

[13] T. Walsh, H. V. Worthington, A.-M. Glenny, P. Appelbe, V. C. C. Marinho, and X. Shi, "Fluoride toothpastes of different concentrations for preventing dental caries in children and adolescents," Cochrane Database of Systematic Reviews, no. 1, article CD007868, 2010.

[14] L. Lipták, K. Szabó, G. Nagy, S. Márton, and M. Madléna, "Microbiological changes and caries-preventive effect of an innovative varnish containing chlorhexidine in orthodontic patients," Caries Research, vol. 52, no. 4, pp. 272-278, 2018.

[15] B. M. Souza, D. M. S. Santos, A. S. Braga et al., "Effect of a titanium tetrafluoride varnish in the prevention and treatment of carious lesions in the permanent teeth of children living in a fluoridated region: protocol for a randomized controlled trial," JMIR Research Protocols, vol. 7, no. 1, article e26, 2018.

[16] L. F. Espinosa-Cristóbal, G. A. Martínez-Castañón, J. P. Loyola-Rodríguez et al., "Bovine serum albumin and chitosan coated silver nanoparticles and its antimicrobial activity against oral and nonoral bacteria," Journal of Nanomaterials, vol. 2015, Article ID 420853, 9 pages, 2015.

[17] L. F. Espinosa-Cristóbal, G. A. Martínez-Castañón, E. J. TéllezDéctor, N. Niño-Martínez, N. V. Zavala-Alonso, and J. P. Loyola-Rodríguez, "Adherence inhibition of Streptococcus mutans on dental enamel surface using silver nanoparticles," Materials Science and Engineering: C, vol. 33, no. 4, pp. 2197-2202, 2013.
[18] A. Besinis, S. D. Hadi, H. R. Le, C. Tredwin, and R. D. Handy, "Antibacterial activity and biofilm inhibition by surface modified titanium alloy medical implants following application of silver, titanium dioxide and hydroxyapatite nanocoatings," Nanotoxicology, vol. 11, no. 3, pp. 327-338, 2017.

[19] W. K. Jung, H. C. Koo, K. W. Kim, S. Shin, S. H. Kim, and Y. H. Park, "Antibacterial activity and mechanism of action of the silver ion in Staphylococcus aureus and Escherichia coli," Applied and Environmental Microbiology, vol. 74, no. 7, pp. 2171-2178, 2008.

[20] A. E. Hernández-Gómora, E. Lara-Carrillo, J. B. RoblesNavarro et al., "Biosynthesis of silver nanoparticles on orthodontic elastomeric modules: evaluation of mechanical and antibacterial properties," Molecules, vol. 22, no. 9, 2017.

[21] G. Metin-Gürsoy, L. Taner, and G. Akca, "Nanosilver coated orthodontic brackets: in vivo antibacterial properties and ion release," The European Journal of Orthodontics, vol. 39, no. 1, pp. 9-16, 2017.

[22] A. R. Mhaske, P. C. Shetty, N. S. Bhat et al., "Antiadherent and antibacterial properties of stainless steel and NiTi orthodontic wires coated with silver against Lactobacillus acidophilus-an in vitro study," Progress in Orthodontics, vol. 16, no. 1, p. 40, 2015.

[23] J. Y. Choi, C. J. Chung, K. T. Oh, Y. J. Choi, and K. H. Kim, "Photocatalytic antibacterial effect of $\mathrm{TiO} 2$ film of TiAg on Streptococcus mutans," The Angle Orthodontist, vol. 79, no. 3, pp. 528-532, 2009.

[24] A. Besinis, T. de Peralta, and R. D. Handy, "Inhibition of biofilm formation and antibacterial properties of a silver nano-coating on human dentine," Nanotoxicology, vol. 8, no. 7, pp. 745-754, 2014.

[25] Q. T. Tran, V. S. Nguyen, T. K. Hoang et al., "Preparation and properties of silver nanoparticles loaded in activated carbon for biological and environmental applications," Journal of Hazardous Materials, vol. 192, no. 3, pp. 1321-1329, 2011.

[26] G. Vanitha, K. Rajavel, G. Boopathy, V. Veeravazhuthi, and P. Neelamegam, "Physiochemical charge stabilization of silver nanoparticles and its antibacterial applications," Chemical Physics Letters, vol. 669, pp. 71-79, 2017.

[27] L. F. Espinosa-Cristóbal, G. A. Martínez-Castañón, R. E. Martínez-Martínez et al., "Antimicrobial sensibility of Streptococcus mutans serotypes to silver nanoparticles," Materials Science and Engineering: C, vol. 32, no. 4, pp. 896-901, 2012.

[28] R. Bürgers, A. Eidt, R. Frankenberger et al., "The antiadherence activity and bactericidal effect of microparticulate silver additives in composite resin materials," Archives of Oral Biology, vol. 54, no. 6, pp. 595-601, 2009.

[29] A. Y. Grün, J. Meier, G. Metreveli, G. E. Schaumann, and W. Manz, "Sublethal concentrations of silver nanoparticles affect the mechanical stability of biofilms," Environmental Science and Pollution Research, vol. 23, no. 23, pp. 24277-24288, 2016.

[30] W. Lee, K. J. Kim, and D. G. Lee, "A novel mechanism for the antibacterial effect of silver nanoparticles on Escherichia coli," BioMetals, vol. 27, no. 6, pp. 1191-1201, 2014.

[31] M. Lavorgna, I. Attianese, G. G. Buonocore et al., "MMT-supported Ag nanoparticles for chitosan nanocomposites: structural properties and antibacterial activity," Carbohydrate Polymers, vol. 102, pp. 385-392, 2014.

[32] M. A. Gravina, I. H. V. P. Brunharo, C. Canavarro, C. N. Elias, and C. C. A. Quintão, "Mechanical properties of NiTi and 
CuNiTi shape-memory wires used in orthodontic treatment. Part 1: stress-strain tests," Dental Press Journal of Orthodontics, vol. 18, no. 4, pp. 35-42, 2013.

[33] M. A. Gravina, C. Canavarro, C. N. Elias, M. G. A. M. Chaves, I. H. V. P. Brunharo, and C. C. A. Quintão, "Mechanical properties of NiTi and CuNiTi wires used in orthodontic treatment. Part 2: microscopic surface appraisal and metallurgical characteristics," Dental Press Journal of Orthodontics, vol. 19, no. 1, pp. 69-76, 2014.

[34] L. C. L. Jaber, J. A. Rodrigues, F. L. B. Amaral, F. M. G. França, R. T. Basting, and C. P. Turssi, "Degradation of orthodontic wires under simulated cariogenic and erosive conditions," Brazilian Oral Research, vol. 28, no. 1, pp. 1-6, 2014.

[35] N. Schiff, M. Boinet, L. Morgon, M. Lissac, F. Dalard, and B. Grosgogeat, "Galvanic corrosion between orthodontic wires and brackets in fluoride mouthwashes," The European Journal of Orthodontics, vol. 28, no. 3, pp. 298-304, 2006.

[36] D. M. Moreira, J. Oei, H. R. Rawls et al., “A novel antimicrobial orthodontic band cement with in situ-generated silver nanoparticles," The Angle Orthodontist, vol. 85, no. 2, pp. 175-183, 2015.

[37] S. J. Ahn, S. J. Lee, J. K. Kook, and B. S. Lim, “Experimental antimicrobial orthodontic adhesives using nanofillers and silver nanoparticles," Dental Materials, vol. 25, no. 2, pp. 206-213, 2009.

[38] R. Ghorbanzadeh, B. Pourakbari, and A. Bahador, "Effects of baseplates of orthodontic appliances with in situ generated silver nanoparticles on cariogenic bacteria: a randomized, double-blind cross-over clinical trial," The Journal of Contemporary Dental Practice, vol. 16, no. 4, pp. 291-298, 2015.

[39] A. Venugopal, N. Muthuchamy, H. Tejani et al., "Incorporation of silver nanoparticles on the surface of orthodontic microimplants to achieve antimicrobial properties," The Korean Journal of Orthodontics, vol. 47, no. 1, pp. 3-10, 2017. 


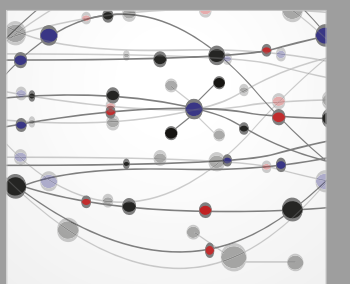

The Scientific World Journal
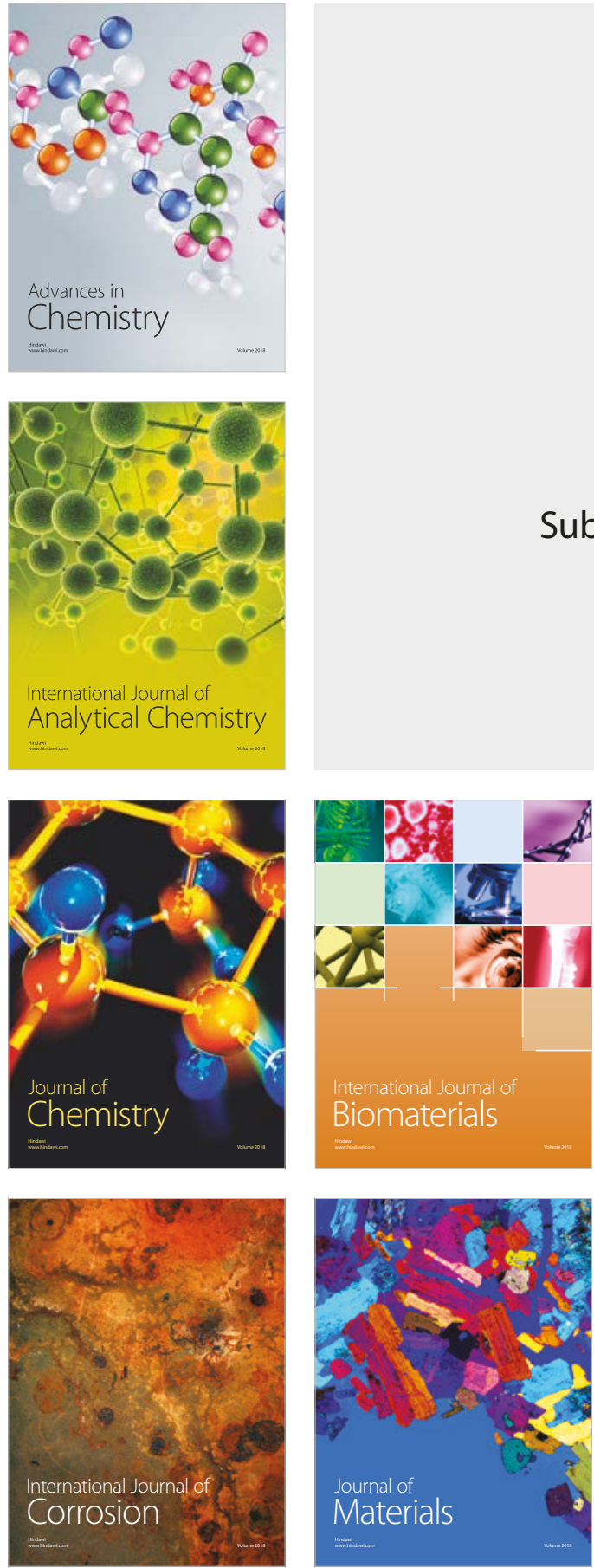

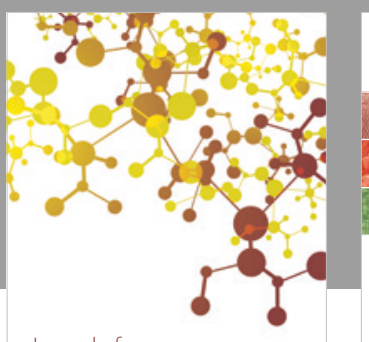

Journal of

Applied Chemistry
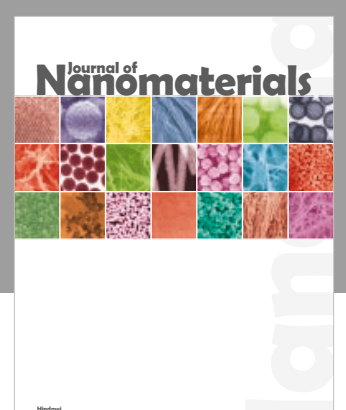

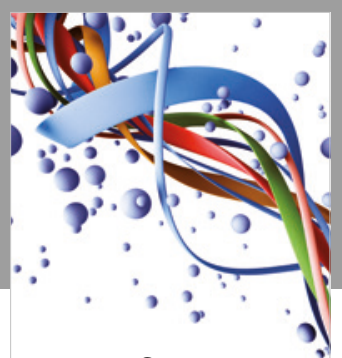

Scientifica

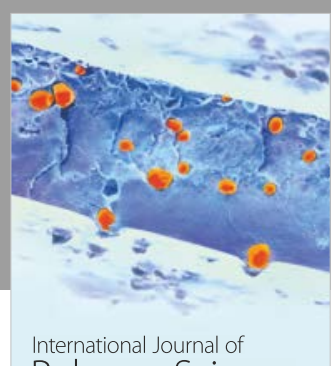

Polymer Science



Physical Chemistry
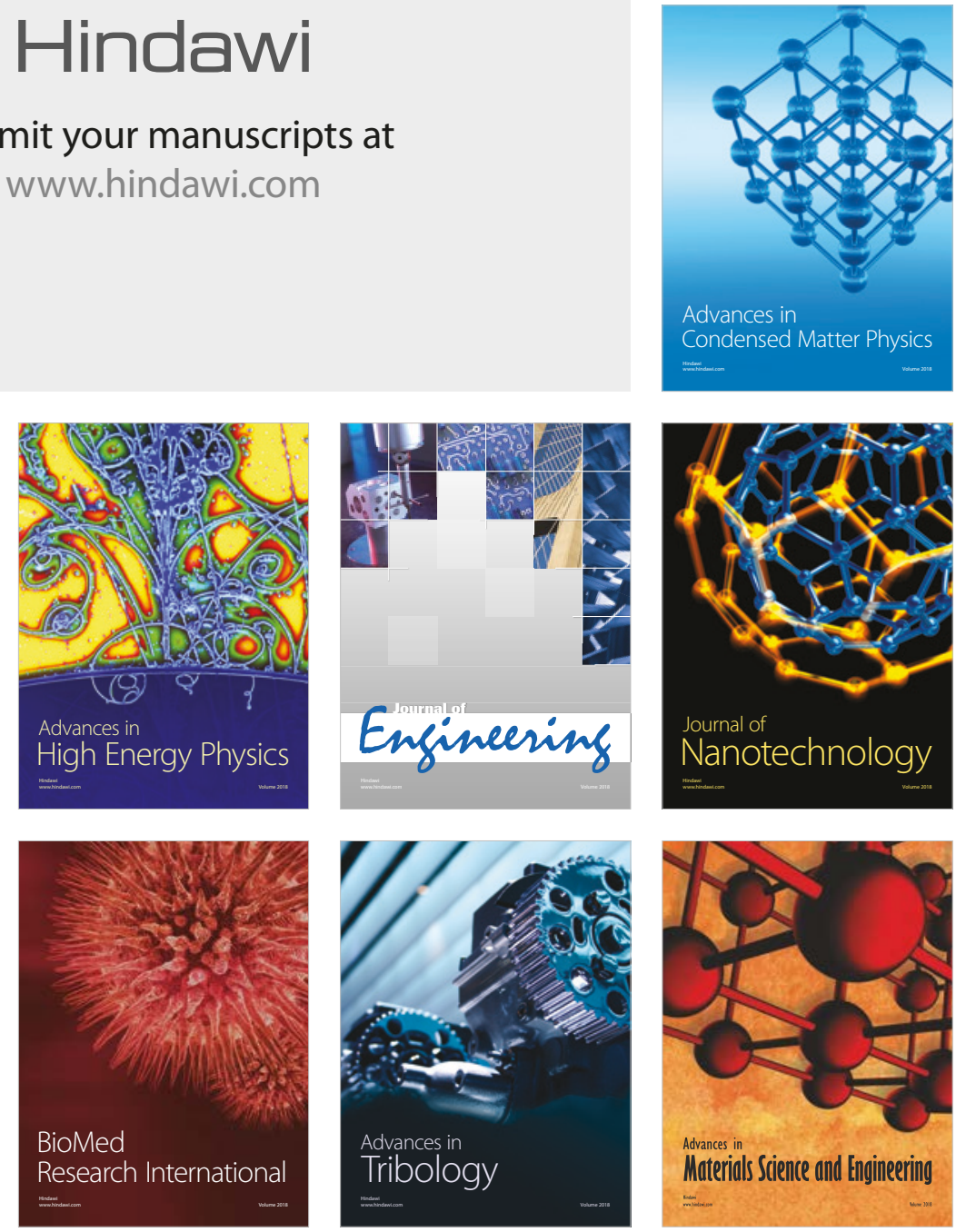